\title{
A new thermocouple technique for the precise measurement of in-plane capillary water flow within
} fabrics

\author{
Chunhong $\mathrm{Zhu}^{1}$ and Masayuki Takatera ${ }^{2 *}$ \\ ${ }^{1}$ Interdisciplinary Graduate School of Science and Technology, Shinshu University, Japan \\ ${ }^{2}$ Faculty of Textile Science and Technology, Shinshu University, Japan \\ *takatera@shinshu-u.ac.jp
}

\begin{abstract}
A new method was proposed for the measurement of in-plane capillary water flow within fabrics automatically. The method was based on the use of thermocouples to measure temperature changes as the fabric absorbed water. The wicking length of three different woven fabrics and two knitted fabrics in the warp, weft and $45^{\circ}$ bias directions was measured using this technique. The wicking length was found to have a linear relationship with the square root of time, in agreement with the Washburn equation. Comparing the results with the data acquired using the horizontal Byreck method, the thermocouple technique was found to be suitable for the precise measurement of in-plane capillary water flow through fabrics automatically. Moreover, based on this method, the feasibility of estimating the water contents of fabrics from temperature differences generated during the flow process was also investigated. We found that it was possible to estimate the water content of a fabric, provided the moisture level is below the critical water content at equilibrium. This can be used to estimate the water content of fabric when it is worn.
\end{abstract}

\section{Introduction}

The transport of liquids through textiles plays an important role in their applications. In general, wetting is the displacement of a solid-air interface by a solid-liquid interface. The motion of a liquid through a fibrous assembly, such as yarn or fabric, may be driven by external forces or solely by capillary action. The spontaneous transport of a liquid driven into a porous system by capillary forces is termed "wicking". Because capillary forces are caused by wetting, wicking is essentially the outcome of spontaneous wetting in a capillary system ${ }^{1-3}$. Wicking takes place only in wet fabrics or when fabrics come into contact with water, and the contact angle determines their wicking behavior. A lower contact angle results in higher wicking rates $^{4}$.

Wicking in fabrics has been widely researched both in academia and industry because it plays an important role in many textile applications, including the design and use of sports wears and industrial uniforms, as well as in various processes such as dyeing, finishing and filtration. In applications such as active sportswear, exercise garments, work clothing, intimate apparel, and footwear, the concept of moisture management is utilized to prevent or minimize the collection of liquids on the skin of the wearer due to perspiration. This is done by quickly wicking of diffusing the liquid through a hydrophobic fibre inner layer to an outer hydrophilic layer and then evaporated it to the atmosphere ${ }^{5}$.

A variety of techniques are used to experimentally study wicking in fabrics, the simplest of which consists of following the movement of liquid throughout the textile structure by using colored water, camera or image analysis techniques and so on ${ }^{2,3,6-15}$. This can be performed when the fabric is perpendicular to, and partly immersed, in a liquid bath or when a drop of liquid is applied to a fabric or yarn and subsequently spreads. The Byreck method, or DIN 53924 $4^{11,15,16}$ is a conventional method of assessing the water absorbency of fabrics. This method is to use a preconditioned strip of the test fabric, suspended vertically with its lower end immersed in a reservoir of distilled water, to which may be added a dye (of a type known not to affect the wicking behavior) for tracking the movement of water. After a fixed time has elapsed, the height reached by the water in the fabric above the water level in the reservoir is measured. However, when applying this method, it is important to take into consideration the influence of the dye applied to color the liquid on the absorption properties of the fabric, as well as variances in the apparent liquid flow front caused by different observational positions and the effects of gravity ${ }^{17}$. Although present-day photographic and image analysis technologies can easily track the surface capillary flow within a fabric, these technologies are 
not always suitable in the case of multilayers, thick fabrics or composite materials. An alternate technique is to weigh the fabric or yarn during capillary wicking ${ }^{18,19}$. However, this method is too sensitive to use with yarns, since in these textiles the wetting force exceeds the effects of capillary forces ${ }^{2,9}$, and it will not show the effect of capillary exactly. Yet another approach consists of measuring the wicking length by applying liquid-sensitive sensors, which track electrical capacitance, humidity and other factors, at regular intervals along the fabric ${ }^{17,20,21}$. This approach also has some associated challenges: the sensors are expensive, and are not suitable for testing fabrics while they are being worn, and may have limited durability.

In the work reported herein, a new method of experimentally measuring capillary liquid flow by using thermocouple array was developed, based on previous studies of temperature variations in fabrics during the wetting and drying processes ${ }^{22}$. As each thermocouple is physically very small and measures temperature over a correspondingly small area, thermocouple array have numerous potential applications, not only in studying liquid water transport but also in following textile water content in real-time. By employing removable, flexible thermocouples, this method can be used to determine the wicking length of liquid moving through fabrics over time without the requirement to add dyes to the liquid. It is also adaptable to many different textile structures, including woven and nonwoven fabrics, as well as yarns. Moreover, this method can be applied to thick fabrics simply by modifying the thermocouple measurement points. The aim of this work was therefore to design and test a new experimental technique for measuring capillary liquid flow, and to investigate the viability of applying this method to estimate the water contents of fabrics.

\section{Basic Theory}

The kinetics of wicking in textiles is critical in many applications and is often investigated by fitting the experimental data to the well-known Washburn equation ${ }^{23}$. Over short spans of time, when the effects of gravity are neglected and when the extent of liquid flow is significantly less than the maximum equilibrium length, the Washburn equation ${ }^{24,25}$ states that the capillary water flow rate depends on the rheological properties of the liquid and the geometry of the capillary spaces and the surface tension between liquid and vapour, as shown in Figure 1.

The Poiseuille's equation is given by Equation (1),

$$
\frac{d L}{d t}=\frac{R^{2} \Delta P}{8 \eta L}
$$

where $L$ is the wicking length, $t$ is time, $R$ is the equivalent radius of the capillary space, and $\eta$ is the liquid viscosity. $\Delta P$ is the capillary pressure difference, which can be obtained by Equation (2).

$$
\Delta P=\frac{2 \gamma \cos \theta}{R}-\rho g h_{0}
$$

where $\gamma$ is the liquid-vapour surface tension, $\theta$ is the contact angle of the solid-liquid system, $\rho$ is the volume density of fluid, $g$ is the gravitational acceleration, and $h_{0}$ is the distance between water level in the fluid reservoir and fabric laid horizontally (the first measurement point).

Integrating Equation (1) with initial condition of $L=0$ at $t=0$, and substituting Equation (2) for $\Delta P$, Equation (3) can be obtained.

$$
L^{2}=\frac{R^{2}}{4 \eta}\left(\frac{2 \gamma \cos \theta}{R}-\rho g h_{0}\right) t
$$

As $h_{0}$ is very slight, in order to simplify the calculation, the horizontal wicking distance of the water is therefore given by Equation (4) below. 


$$
L=(R \gamma \cos \theta / 2 \eta)^{1 / 2} t^{1 / 2}
$$

According to Equation (4), a plot of $L$ versus $t^{1 / 2}$ should be linear and pass through the origin. The slope of the line, referred to as the wicking coefficient $W_{c}$, is given by Equation (5) and is determined by fitting the experimental data to Equation (4).

$$
W_{c}=(R \gamma \cos \theta / 2 \eta)^{1 / 2}
$$

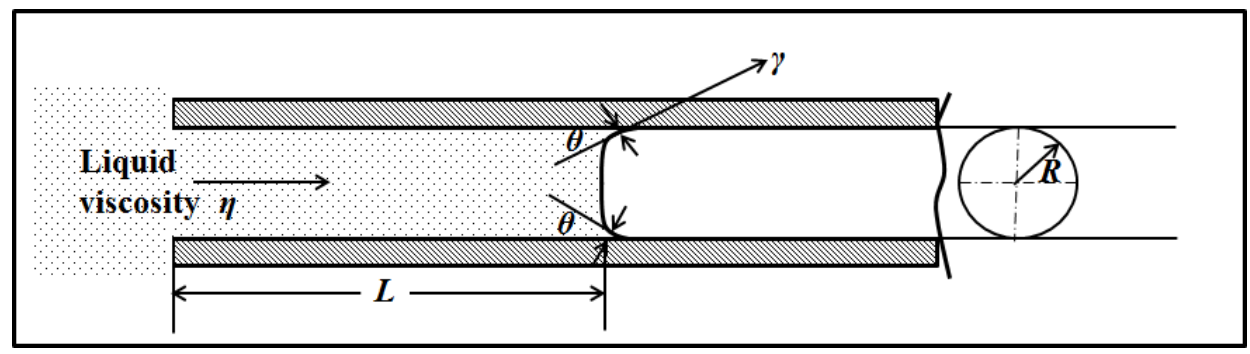

Figure 1. Capillary action.

\section{Experimental}

The experimental trials were divided into two parts. The initial trials verified the applicability of the new experimental technique of using thermocouple array to measure capillary liquid flow, while subsequent work investigated the feasibility of employing this method to estimate the equilibrium water contents of wetted fabrics.

\section{Experiments for measuring capillary liquid flow}

Test apparatus. Figure 2 presents diagrams of the test apparatus used to measure capillary liquid flow through the fabrics. The apparatus consisted of an array of nine thermocouple measurement points set 10 $\mathrm{mm}$ apart and sitting on foam polystyrene for heat insulation. The thermocouples were Type T, made from copper and constantan element wires of $0.1 \mathrm{~mm}$ in diameter ${ }^{22}$. The standard temperature range is from $-200^{\circ} \mathrm{C}$ to $350^{\circ} \mathrm{C}$, and the accuracy of the thermocouple is within $0.5^{\circ} \mathrm{C}$. The temperature data were collected and recorded in a sampling rate of $5 \mathrm{~s}^{-1}$, or 5 data points per second automatically.

For the woven fabric, the wetted end of the fabric strip was clipped to a weight that produced a tension of $5.0 \mathrm{gf} / \mathrm{cm}^{17}$. This functioned both to keep the fabric end immersed in the $20 \pm 1^{\circ} \mathrm{C}$ ion-exchanged water and to ensure the rest of the fabric strip remained in contact with the sensor array. The absolute minimum amount of tension necessary was applied, since excess tension can strain the fabric and alter its wicking performance. For the knit fabric, because it is stretchy, a slight tension may cause the stretch of fabric, the tension for it was only its own weight. The other end of the fabric was fixed so as to keep it taut throughout the experimental trial. The water level in the fluid reservoir was maintained at a constant height by perforating a hole on the reservoir to keep the water level the same before each experimental trial and suppressing water evaporation during the experiment. As the fabric absorbed water, changes in temperature were measured by the thermocouple array. 


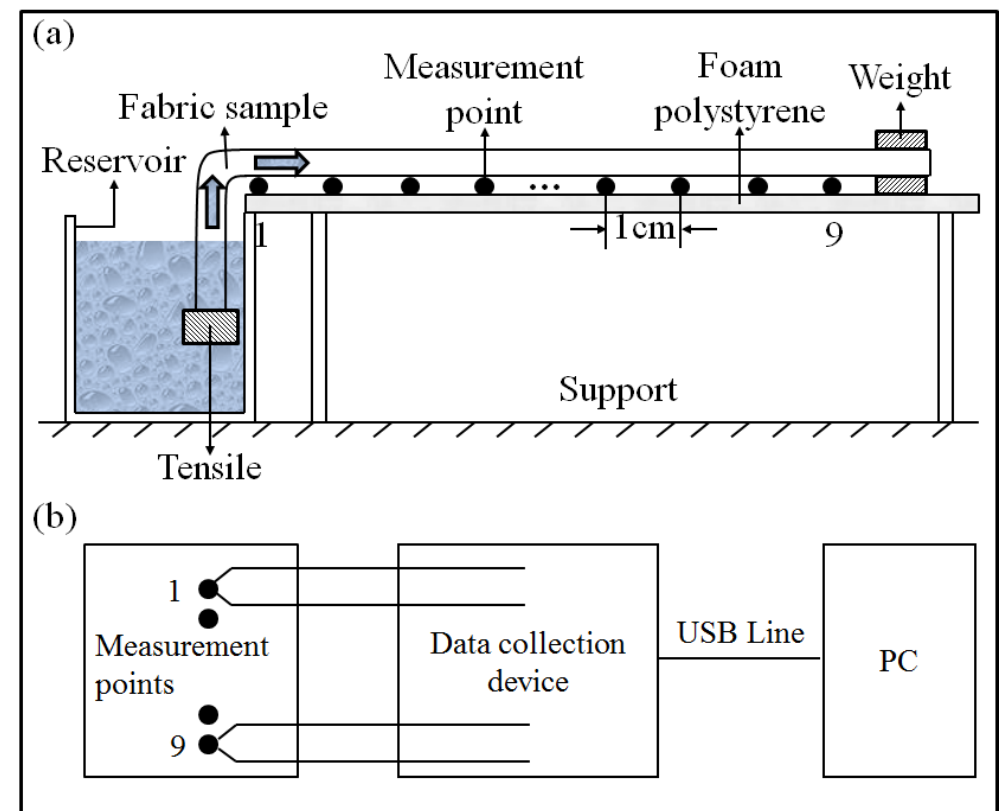

Figure 2. Thermocouple test apparatus: (a) Schematic diagram of thermocouple method; (b) Block diagram of the overall system.

Principle of the measurement. The temperature of the fabric at the liquid flow front will change during the process of water absorption because of heat transference associated with both wetting and evaporation. As the fabric initially absorbs water, wetting heat is generated and the local temperature temporarily increases, after which it begins to drop ${ }^{22}$. These temperature variations are measured by the thermocouple at each measurement point and are relayed to and recorded by a computer.

Figure 3 shows the relationship between temperature and time during the liquid flow process of a cotton/polyester fabric. Because of absorption heat, the fabric temperature increases, and then it goes down for the reason of evaporation larger than absorption till it reaches about the wet bulb temperature ${ }^{22}$.

Since the fabric temperature will rise because of the absorption of liquid, if the temperature $T$ at time $t$ increases to $0.5^{\circ} \mathrm{C}$ in less than 10 seconds, then $t$ is defined as the arrival time, as shown in Figure (3). The 10 seconds time scale was determined on the basis of measurement error and the stability of measured temperature. If the temperature at time $t$ increases to $0.5^{\circ} \mathrm{C}$ at $t_{T+0.5}$ in which the interval is more than 10 seconds, then the arrival time is defined as Equation (6). However, if the wetting heat is minimal compared with heat loss via evaporation, then the temperature at the flow front will decrease. In this case, the arrival time of the flow front is defined as the time at which the temperature is $0.5^{\circ} \mathrm{C}$ greater than the temperature at time $t+10$ (s), as shown in Equation (7).

$$
\begin{aligned}
& t_{n}=t_{T+0.5^{\circ} \mathrm{C}}-10 \mathrm{~s} \\
& t_{n}=t_{T-0.5^{\circ} \mathrm{C}}-10 \mathrm{~s}
\end{aligned}
$$

Here $T\left({ }^{\circ} \mathrm{C}\right)$ is the temperature at the arrival time $t(\mathrm{~s})$. As nine measurement points are set in this experiment, $n$ refers to 1 to 9 .

As shown in figure 3, the time required for liquid flow between any two measurement points $n$ and $n+1$ can be calculated according to Equation (8).

$$
\Delta t_{n \rightarrow n+1}=t_{n+1}-t_{n}, n=1,2 \cdots 8
$$

The overall time $\left(\right.$ Time $\left._{n}\right)$ from the zero of the flow time to the point $n+1$ can be calculated according to Equation (9). 


$$
\text { Time }_{n}=\Delta t_{1 \rightarrow 2}+\Delta t_{2 \rightarrow 3}+\cdots+\Delta t_{n \rightarrow n+1}
$$

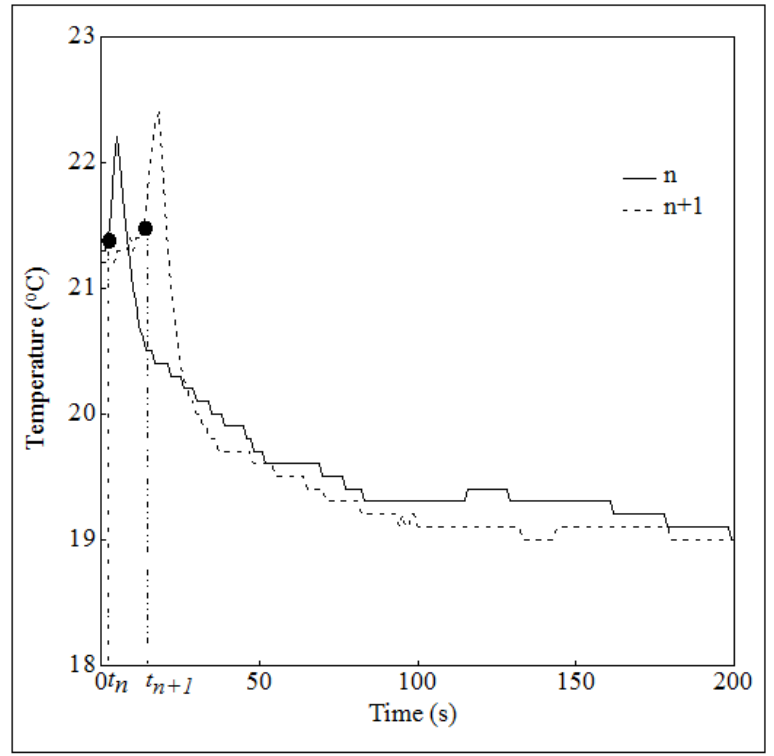

Figure 3. Temperature variations over time in a cotton/polyester fabric.

Test samples. Three kinds of plain woven fabrics and two kinds of knitted fabrics were used in this work, with the specifications shown in Table 1.

Prior to testing, fabric samples were washed with soap for 35 minutes, then rinsed with water for 50 minutes to prevent soap remaining on the fabric samples, and dried by air at constant environmental condition of $20 \pm 1^{\circ} \mathrm{C}$ and a constant relative humidity (RH) of $65 \pm 2 \%$. Then test specimens $(25$ by $3 \mathrm{~cm}$ ) were carefully cut from each fabric at varying locations along the warp, weft and $45^{\circ}$ bias directions. Experiments were performed at a constant temperature of $20 \pm 1^{\circ} \mathrm{C}$ and a constant relative humidity (RH) of $65 \pm 2 \%$. Five samples for each direction of each fabric were tested, and the averages and standard deviations were determined. A diagram of a typical fabric strip sample as used in these trials is presented in Figure 4. The portion of the fabric that is bent towards the water reservoir is $5 \mathrm{~cm}$ long, and 4.7 and $4.8 \mathrm{~cm}$ length of it is immersed in the ion-exchanged water, while the horizontal section is $9 \mathrm{~cm}$ and is marked at 1 $\mathrm{cm}$ intervals.

To assess the validity of our new measurement technique, we simultaneously applied the horizontal Byreck method $^{26}$ to measure liquid flow through the same fabrics. In the following discussions, we refer to this protocol as the Byreck method and the new technique simply as the thermocouple method.

Table 1. Specifications of test samples

\begin{tabular}{|c|c|c|c|c|c|c|}
\hline \multicolumn{2}{|l|}{ Sample name } & $\mathrm{C}$ & $\mathrm{C} / \mathrm{P}-1$ & $\mathrm{C} / \mathrm{P}-2$ & C-k & P-k \\
\hline \multicolumn{2}{|l|}{ Fiber content } & $100 \%$ Cotton & $\begin{array}{l}35 \% \text { Cotton } \\
65 \% \\
\text { Polyester }\end{array}$ & $\begin{array}{l}35 \% \text { Cotton } \\
65 \% \\
\text { Polyester }\end{array}$ & $\begin{array}{l}100 \% \\
\text { Cotton }\end{array}$ & $\begin{array}{l}100 \% \\
\text { Polyester }\end{array}$ \\
\hline \multicolumn{2}{|l|}{ Fabric type } & Woven & Woven & Woven & Weft knit & Weft knit \\
\hline Yarn count (tex) & $\begin{array}{l}\text { Warp } \\
\text { Weft }\end{array}$ & $\begin{array}{l}28.0 \\
28.0\end{array}$ & $\begin{array}{l}12.5 \\
14.5\end{array}$ & $\begin{array}{l}13.5 \\
13.5\end{array}$ & 24 & 21 \\
\hline $\begin{array}{l}\text { Fabric density } \\
\left(\mathrm{cm}^{-1}\right)\end{array}$ & $\begin{array}{l}\text { Warp/Wale } \\
\text { Weft/Course }\end{array}$ & $\begin{array}{l}27 \\
22\end{array}$ & $\begin{array}{l}56 \\
28\end{array}$ & $\begin{array}{l}56 \\
28\end{array}$ & $\begin{array}{l}27 \\
18.5\end{array}$ & $\begin{array}{l}32.5 \\
22\end{array}$ \\
\hline \multicolumn{2}{|c|}{ Mass per unit area $\left(\mathrm{g} / \mathrm{m}^{2}\right)$} & 153.52 & 114.60 & 111.02 & 176 & 165 \\
\hline \multicolumn{2}{|l|}{ Thickness (mm) } & 0.745 & 0.442 & 0.569 & 1.02 & 1.03 \\
\hline \multicolumn{2}{|l|}{ Porosity $^{2}$} & 86.62 & 82.53 & 86.41 & 88.80 & 88.39 \\
\hline
\end{tabular}




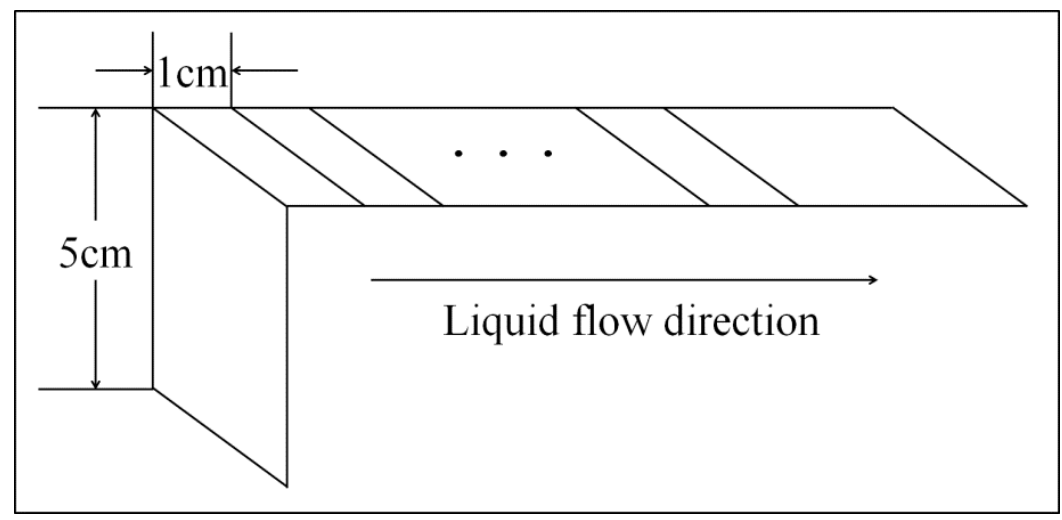

Figure 4. Diagram of a typical fabric sample as used in water flow trials.

\section{Predicting water content based on temperature differences in fabrics}

Initially, experimental trials were carried out with the aim of investigating the relationship between fabric temperature and water content, using square sections of fabric. Moreover, the relationship between water content and difference of fabric and room temperatures will be obtained, which will be used for estimating water content from the temperature difference.

Prior to each trial, test specimens were wetted by soaking in distilled water for 24 hours and squeezed to make sure no water dripped from the fabric. Then lay the fabrics on the foam polystyrene placed on the balance, which was set zero at the beginning of the experiment. The mass and temperature of each wetted specimen were measured and recorded during the subsequent drying process. The continuous mass was measured and recorded by the GF-600 balance (A\&D Company, Limited), with the resolution of 0.001g. The temperature was measured and recorded by three thermocouples with the measurement points set between two fabrics.

We next carried out experimental trials designed to investigate the relationship between temperature and water content at different locations along the fabrics when water flow had reached equilibrium.

Measurements of the equilibrium wicking lengths were performed using the same apparatus as shown in Figure 2, applying thermocouple measurement points as summarized in Figure 5. The first measurement point was located immediately adjacent to the water reservoir, followed by additional ten measurement points every $3 \mathrm{~cm}$ and then eleven measurement points at $1 \mathrm{~cm}$ intervals. Fabric specimens $55 \mathrm{~cm}$ in length and $3 \mathrm{~cm}$ wide were used and the equilibrium wicking length was determined by dipping a $4.5 \mathrm{~cm}$ end portion of the sample in a water reservoir for 12 hours $^{23}$. Temperatures along the fabric at the thermocouple measurement points were recorded during this time period, and the temperature of each measurement point was assumed to be the average temperature of the segment to which the measurement point was attached. The temperature difference of the fabric at each segment was calculated by subtracting the measured temperature at each measurement point from room temperature.

When the 12 hours wicking time had elapsed, every $1 \mathrm{~cm}$ segment of the fabric centered on each of the thermocouple measurement points was cut off and weighed to calculate the water content. The water content of each section of fabric $(M)$ was calculated using Equation (10).

$$
M=\frac{W_{1}-W_{2}}{W_{2}} \times 100 \%
$$

Here, $W_{1}$ is the mass of the wet fabric segment immediately after being removed from the test specimen, and $W_{2}$ is the mass of the same fabric segment after drying.

A $100 \%$ cotton fabric (C) was used in these experiments and six trials were performed along the weft direction at a constant temperature of $20 \pm 1{ }^{\circ} \mathrm{C}$ and $65 \pm 2 \% \mathrm{RH}$. 


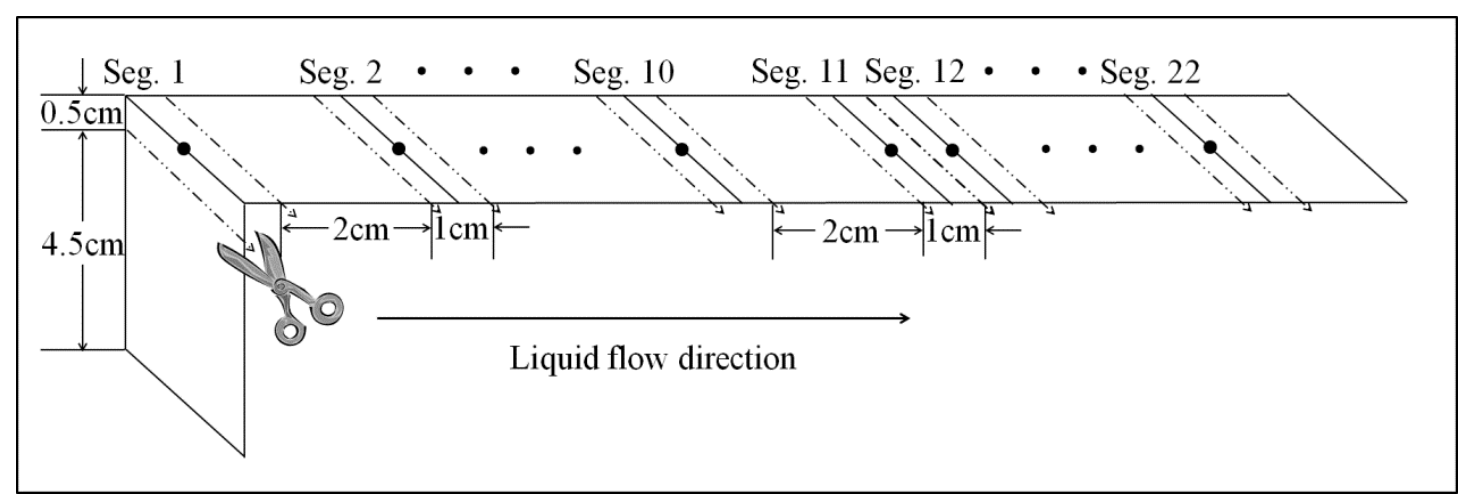

Figure 5. A typical fabric strip sample as used in equilibrium water flow trials, showing thermocouple locations.

\section{Results and Discussion}

\section{The feasibility of the thermocouple method}

Figure 6(a) summarizes the results of measurements of wicking length over time during wetting of cotton fabric in the warp direction, as measured by both the thermocouple array and the Byreck method. Figure 6(b) plots the same results but against the square root of time, which Equation (4) suggests should produce a straight line.

It is evident that both methods generated data showing essentially the same trends: as wetting time increases, so does wicking length. Equation (4) predicts that the wicking length will be zero at time zero, although, as shown in Figure 2, there is a finite distance between the water surface and the nearest measurement point, and so these plots do not go through the origin. Figure 6(b) shows that the plots of wicking length versus square root of time are highly linear, with coefficients of determination above 0.99 , in agreement with Equation (4). The wicking coefficient of the cotton fabric can be obtained from these data, and values of 0.3099 and 0.3084 are calculated from the thermocouple and Byreck method data, respectively. There is evidently a slight difference between the two methods such that, at the same wicking length, the time measured by the thermocouple method is slightly shorter than that determined by the Byreck method. This is mainly because the Byreck method requires that the water front be determined by visual analysis of color change, and so there is an associated time lag between the actual and the observed water front. The thermocouple method, being automated, with a high frequency of data collection, is therefore more precise than the Byreck method. Figure 7 and Figure 8 show the results for cotton fabric (C) in the weft and bias direction, respectively.

Liquid flow throughout the other fabrics (C/P-1, C/P-2 and C-k) was also measured by both the thermocouple array and Byreck techniques. The results were shown from Figure 9 to Figure 17 and very similar results were obtained. Because of the hydrophobicity of polyester knit fabric (P-k), the wicking length is almost zero which cannot be measured and recorded by both techniques. Therefore, the results of polyester fabric cannot be shown.

Table 2 lists the wicking coefficients determined for fabric samples in the warp, weft and $45^{\circ}$ bias directions, as measured by the thermocouple and Byreck methods. The relative differences between the results determined by the two methods $\Delta W_{c}$ are also provided, as calculated according to Equation (11).

$$
\Delta W_{c}=\left|\frac{W_{c(\mathrm{~T})}-W_{c(\mathrm{~B})}}{W_{c(\mathrm{~B})}}\right| \times 100 \%
$$

Here, $W_{c(\mathrm{~T})}$ is the wicking coefficient determined by the thermocouple method and $W_{c(\mathrm{~B})}$ is the wicking coefficient resulting from the Byreck method. As the $\Delta W_{c}$ values in Table 2 demonstrate, the differences between both methods are small. 

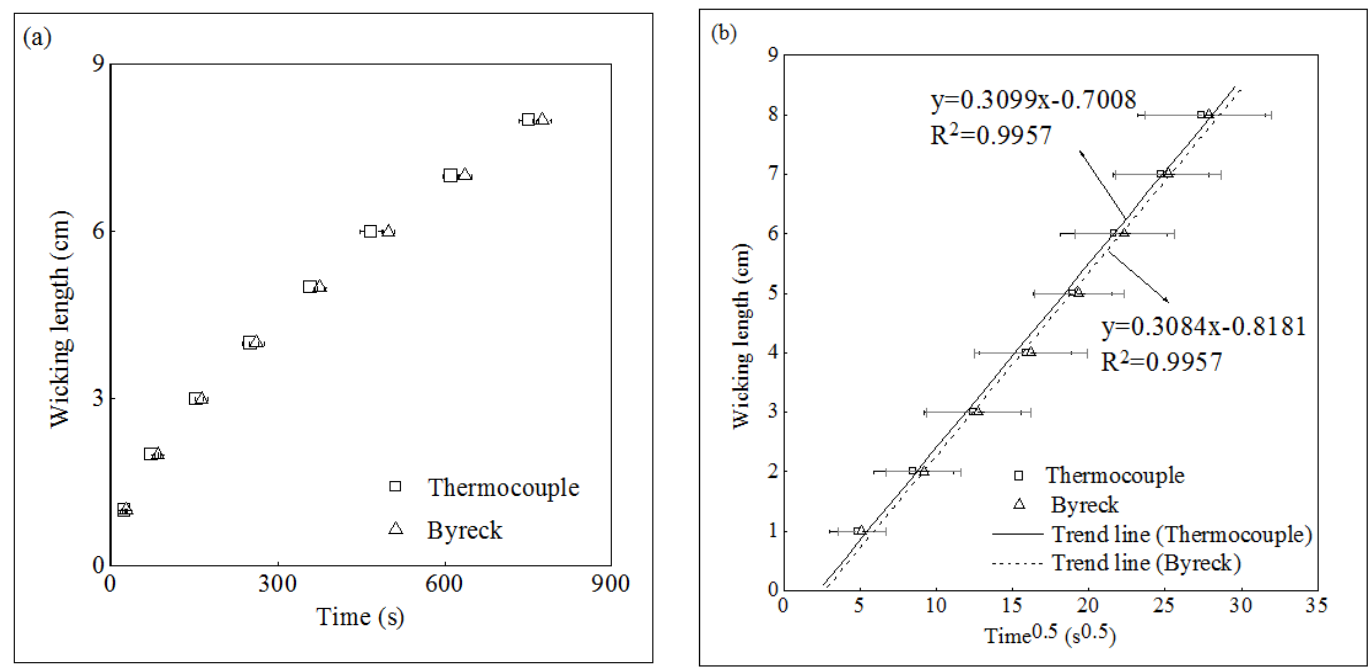

Figure 6. Comparison of the results of thermocouple and Byreck measurements for cotton fabric in the warp direction: (a) Relationship between the wicking length and time; (b) Relationship between wicking length and square root of time.
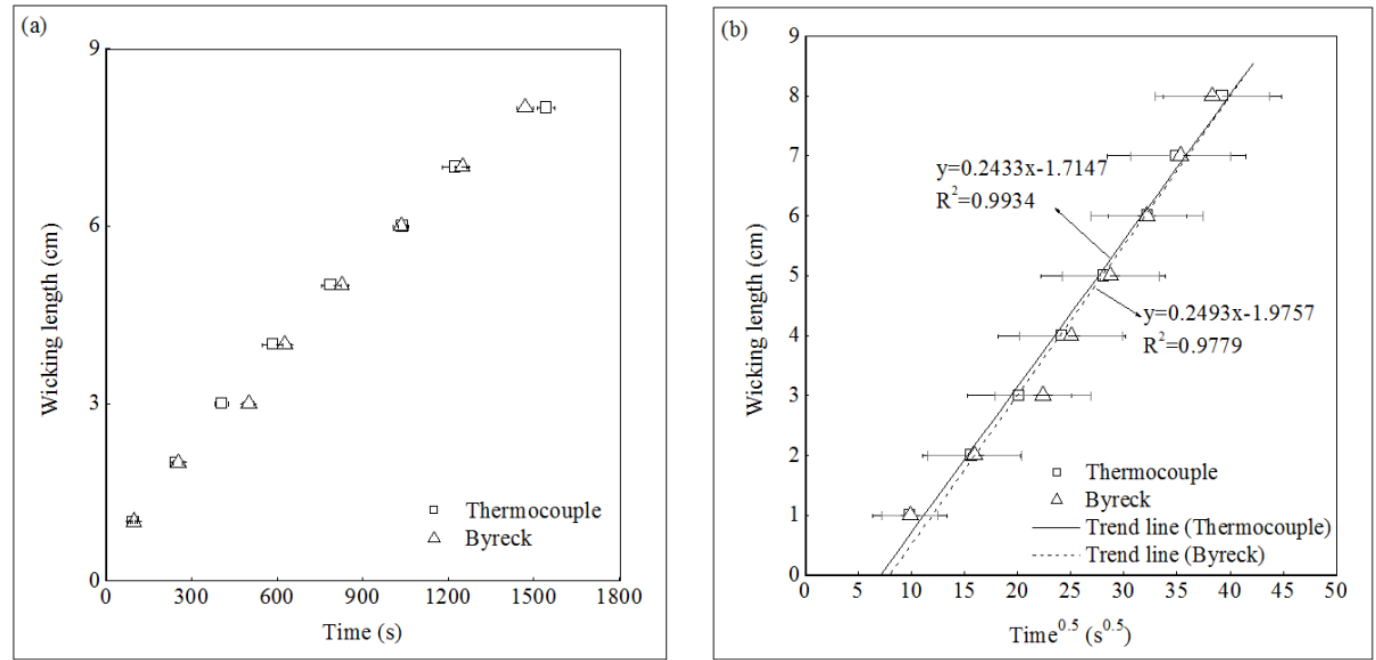

Figure 7. Comparison of the results of the two measurements for cotton fabric in the weft direction: (a) Relationship between the wicking length and time; (b) Relationship between wicking length and square root of time.
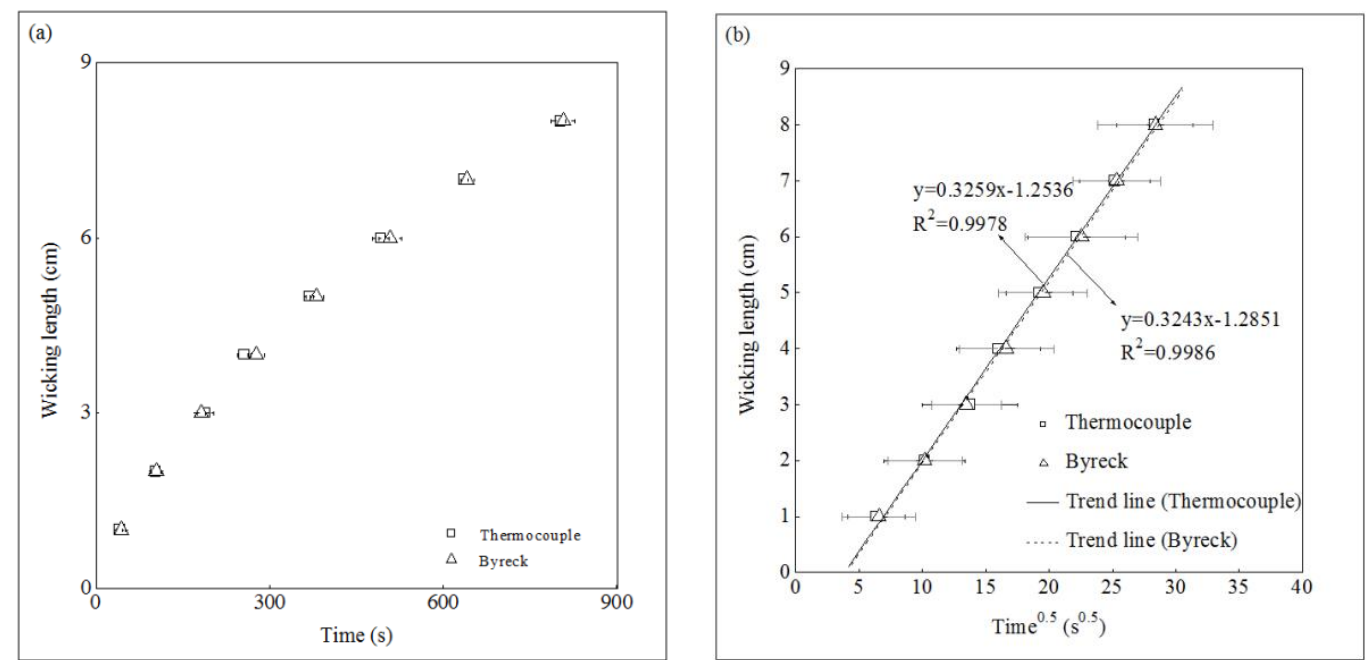

Figure 8. Comparison of the results of the two measurements for cotton fabric in the $45^{\circ}$ bias direction: (a) Relationship between the wicking length and time; (b) Relationship between wicking length and square root 
of time.
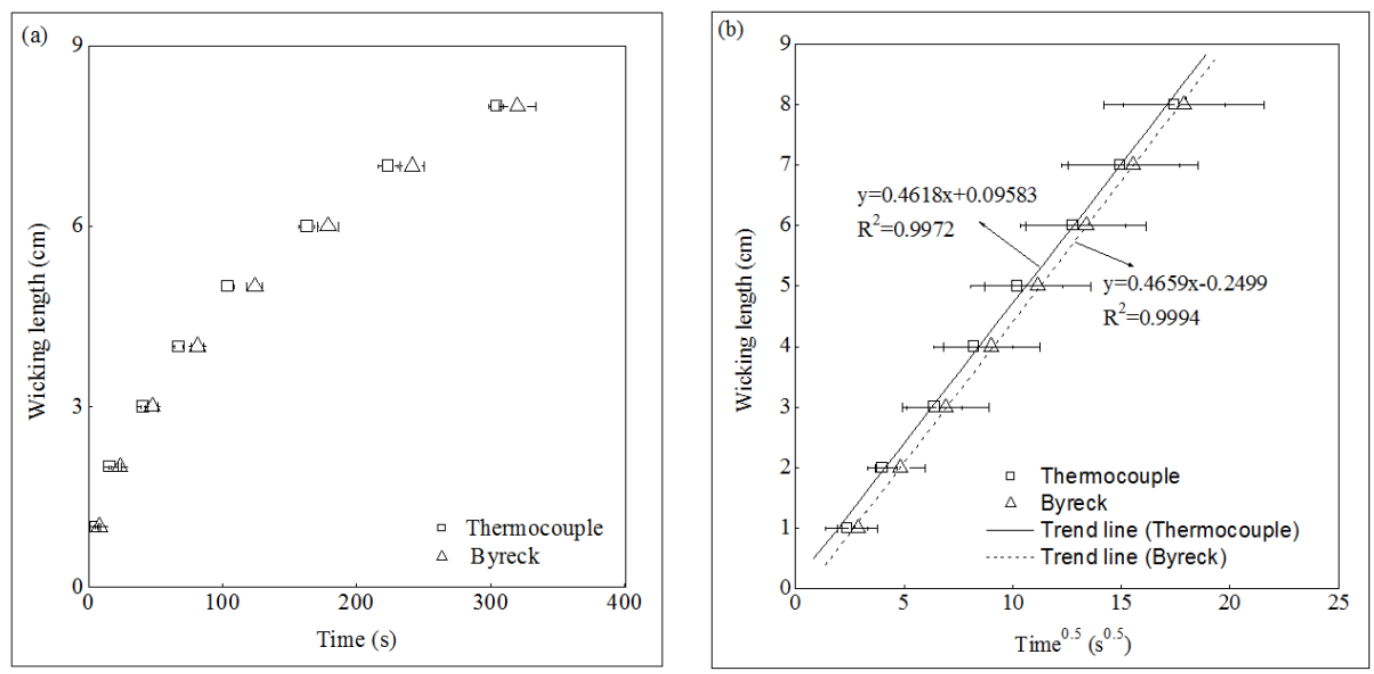

Figure 9. Comparison of the results of the two measurements for cotton/polyester fabric (C/P-1) in the warp direction: (a) Relationship between the wicking length and time; (b) Relationship between wicking length and square root of time.
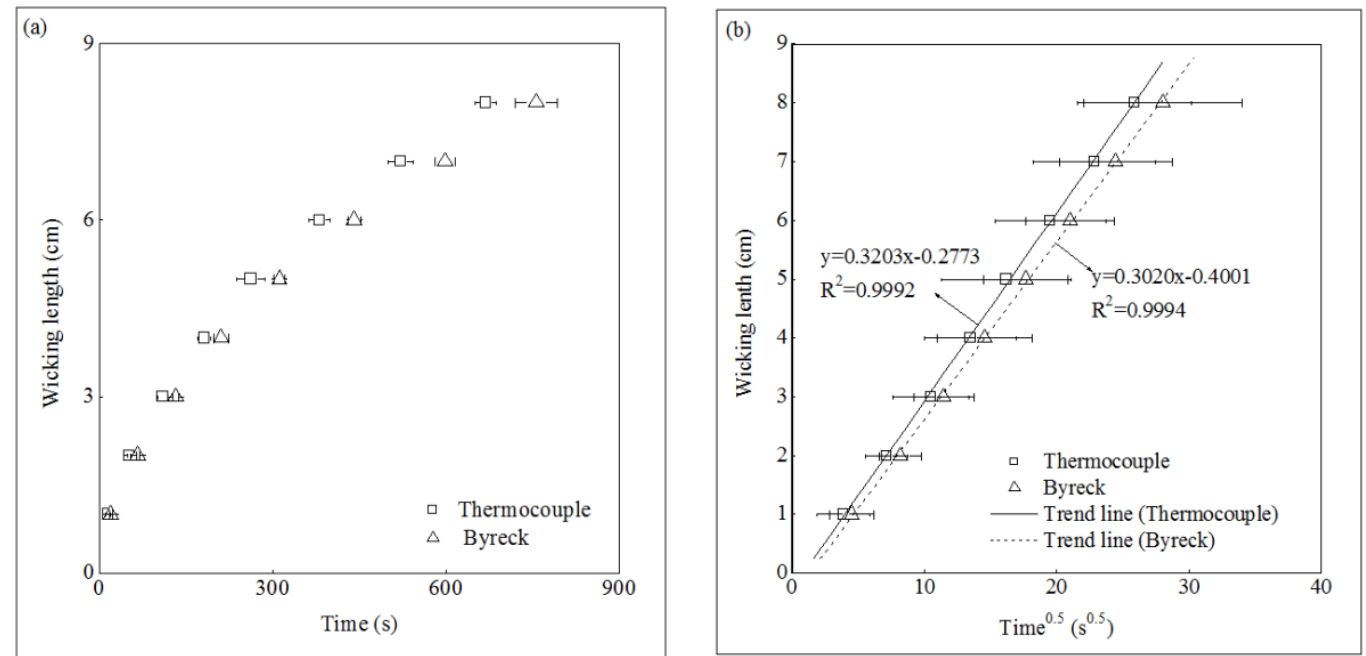

Figure 10. Comparison of the results of the two measurements for cotton/polyester fabric (C/P-1) in the weft direction: (a) Relationship between the wicking length and time; (b) Relationship between wicking length and square root of time. 

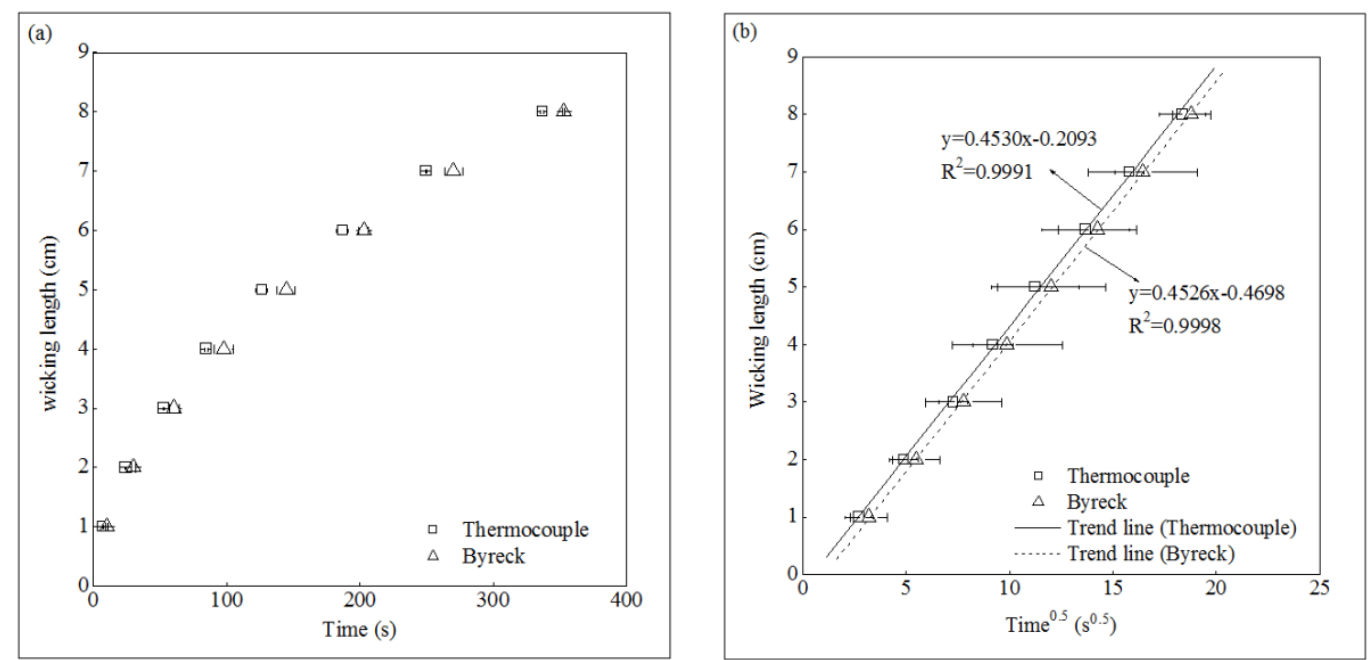

Figure 11. Comparison of the results of the two measurements for cotton/polyester fabric ( C/P-1) in the bias direction: (a) Relationship between the wicking length and time; (b) Relationship between wicking length and square root of time.
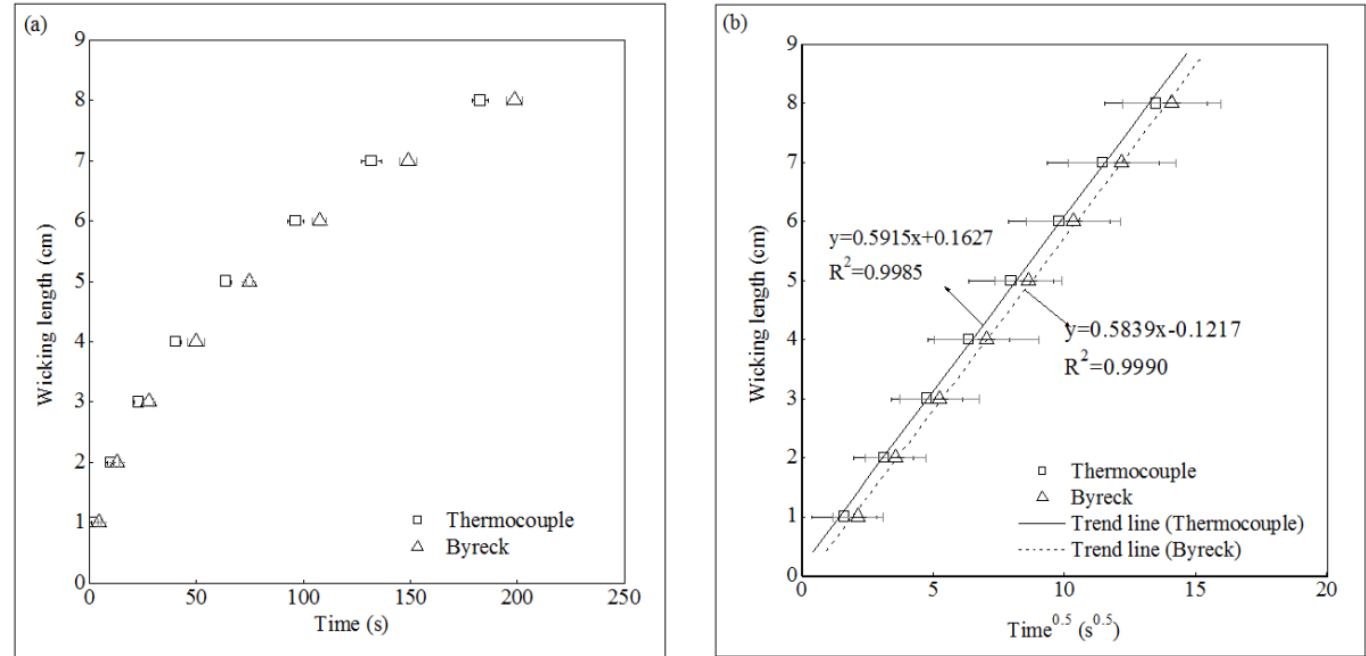

Figure 12. Comparison of the results of the two measurements for cotton/polyester fabric (C/P-2) in the warp direction: (a) Relationship between the wicking length and time; (b) Relationship between wicking length and square root of time.
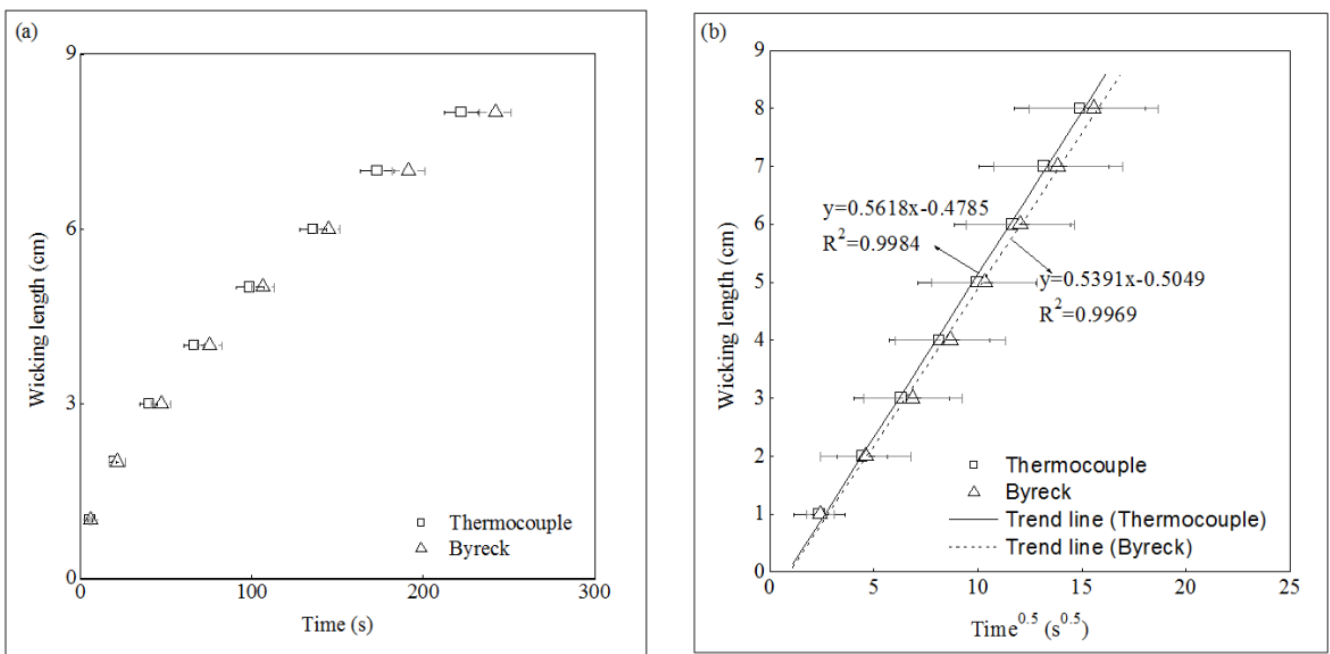

Figure 13. Comparison of the results of the two measurements for cotton/polyester fabric (C/P-2) in the weft direction: (a) Relationship between the wicking length and time; (b) Relationship between wicking length 
and square root of time.
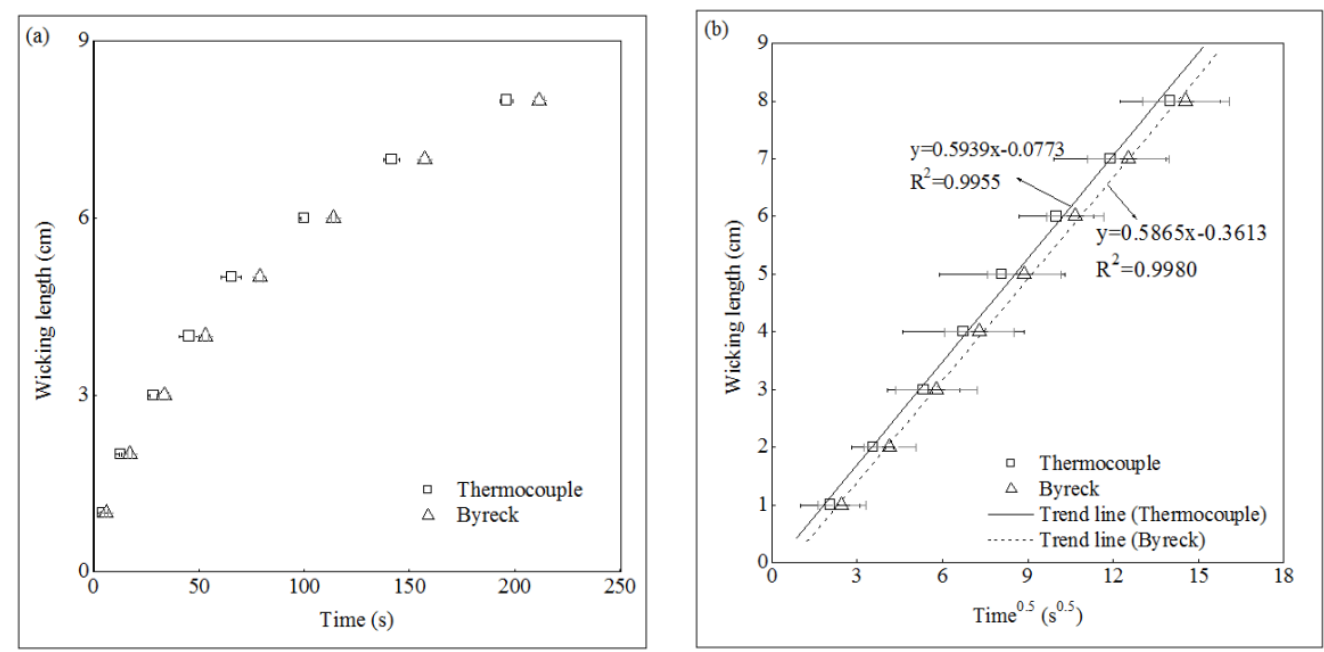

Figure 14. Comparison of the results of the two measurements for cotton/polyester fabric (C/P-2) in the bias direction: (a) Relationship between the wicking length and time; (b) Relationship between wicking length and square root of time.
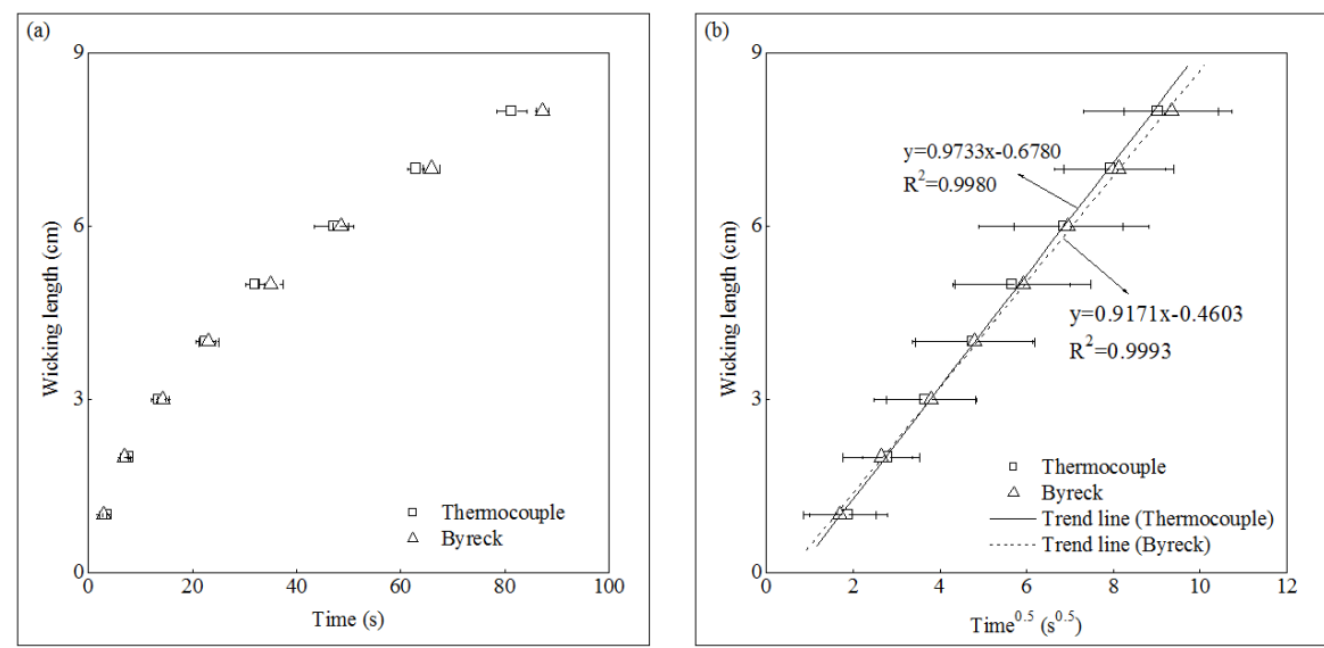

Figure 15. Comparison of the results of the two measurements for cotton knit fabric (C-k) in the warp direction: (a) Relationship between the wicking length and time; (b) Relationship between wicking length and square root of time.
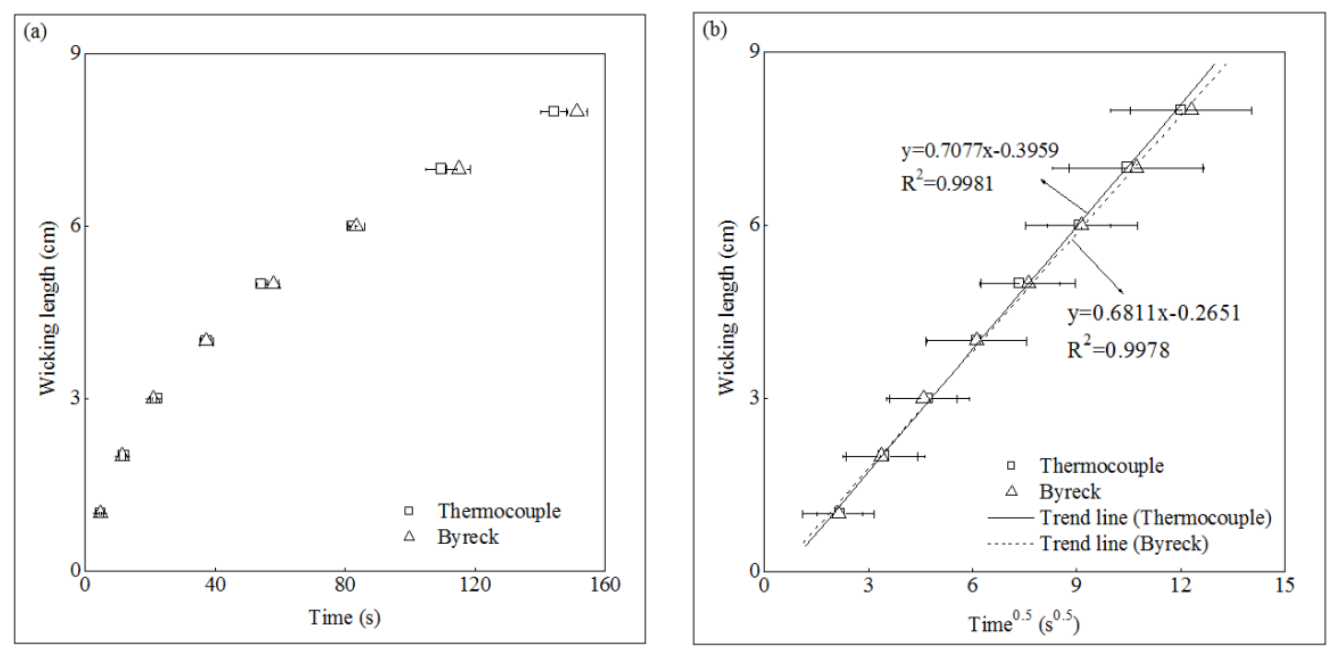

Figure 16. Comparison of the results of the two measurements for cotton knit fabric (C-k) in the weft direction: (a) Relationship between the wicking length and time; (b) Relationship between wicking length and square root of time. 

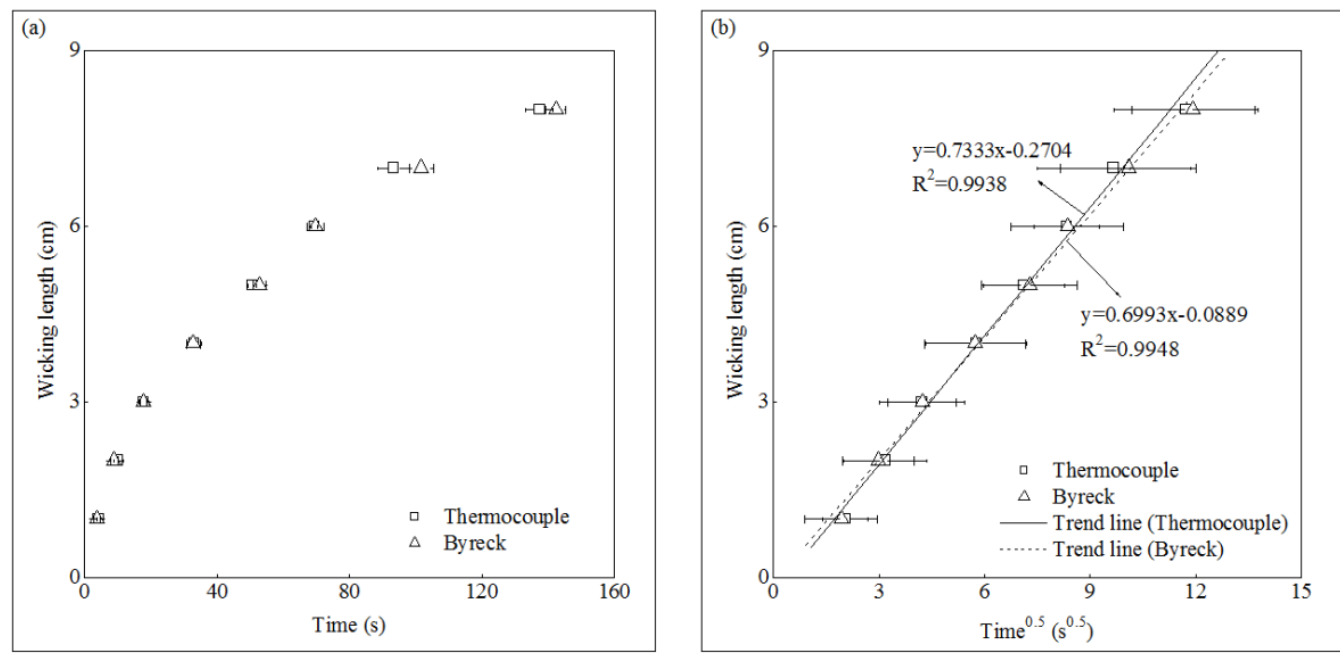

Figure 17. Comparison of the results of the two measurements for cotton knit fabric (C-k) in the bias direction: (a) Relationship between the wicking length and time; (b) Relationship between wicking length and square root of time.

Table 2. Wicking coefficients $\left(\mathrm{cm} / \mathrm{s}^{0.5}\right)$ obtained for fabric samples in three directions with two methods

\begin{tabular}{lllll}
\hline Fabric & Method & Warp & Weft & $45^{\circ}$ bias \\
\hline C & Thermocouple & 0.3099 & 0.2433 & 0.3259 \\
& Byreck & 0.3084 & 0.2493 & 0.3243 \\
C/P-1 & $\Delta W_{c}(\%)$ & 0.4864 & 2.4067 & 0.4934 \\
& Thermocouple & 0.4618 & 0.3202 & 0.4530 \\
& Byreck & 0.4660 & 0.3021 & 0.4526 \\
C/P-2 & $\Delta W_{c}(\%)$ & 0.9013 & 5.9914 & 0.0884 \\
& Thermocouple & 0.5915 & 0.5618 & 0.5939 \\
& Byreck & 0.5839 & 0.5391 & 0.5865 \\
C-k & $\Delta W_{c}(\%)$ & 1.3016 & 4.2107 & 1.2617 \\
& Thermocouple & 0.9733 & 0.7077 & 0.7333 \\
& Byreck & 0.9171 & 0.6811 & 0.6993 \\
& $\Delta W_{c}(\%)$ & 6.1280 & 3.9054 & 4.8620 \\
\hline
\end{tabular}

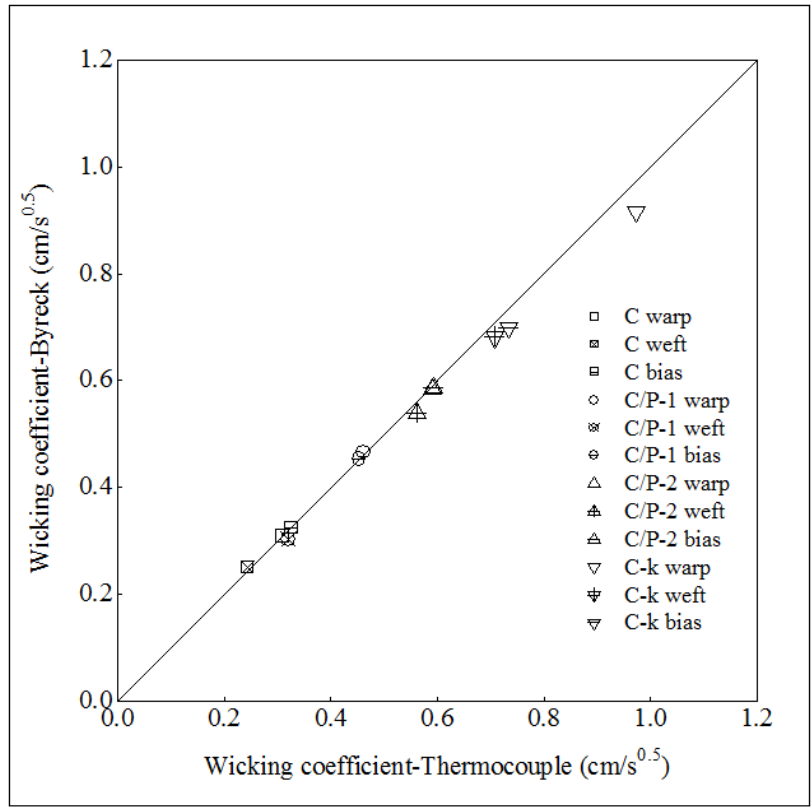

Figure 18. Comparison of wicking coefficient results of different fabric samples in three directions from the thermocouple and Byreck method. 
The comparison of the wicking coefficient results of all samples by both methods are summarized in Figure 18. From this figure, it is evident that the wicking coefficients determined for each fabric are very consistent between the two measurement methods. It can therefore be concluded that our thermocouple array technique is suitable for tracking liquid movement through fabrics. The data generated by the thermocouples also demonstrate the linear relationship between wicking length and the square root of wetting time predicted by the Washburn equation. Based on these results, we are confident that the thermocouple array technique can be used in place of the Byreck method to follow the flow of water within fabrics.

\section{Predicting water content from equilibrium temperature of fabric}

The relationship between the water content and the temperature of each fabric samples during the drying process is shown in Figure 19. For cotton woven fabric (C), the fabric temperature exhibits very little change until the water content approaches approximately 35\%, at which point the temperature increases significantly with further decreases in the fabric's water content. These results reflect a typical drying process. In the first period, the free water at fabric surface evaporates. The drying rate is determined by the diffusion of water vapor from the saturated surface of the fabric through a stationary air film into the air stream. This is the constant rate period which it will maintain for a period of time. Eventually the water content of the material drops to a level known as the critical water content, and there is little free water, then water from the inside of the fabric will transport to the surface and evaporate, until the fabric is dry. This is the falling rate period ${ }^{27-29}$. In this cotton fabric, $35 \%$ water content is evidently the critical water content, which refers to the water content of the fabric at the end of the constant period when the falling rate period begins. Above this level, drying occurs in the constant rate period and fabric temperature is approximately constant, whereas below this level, drying enters the falling rate period and the temperature increases greatly with decreasing water content. The critical water content of cotton/polyester fabric (C/P-1, C/P-2) is about $7 \%$, and for the cotton knit fabric, it is about $35 \%$, too. For polyester knit fabric, the critical water content is about $2 \%$. The differences in critical water content are due to the fiber content of fabric. The cotton fabrics ( $\mathrm{C}$ and $\mathrm{C}-\mathrm{k}$ ) have the highest critical water content, which is caused by more water absorbed by cotton fabric, as well as yarn and fiber. It takes much time for cotton yarn and fiber to release absorbed water and therefore the critical water content is higher than others.

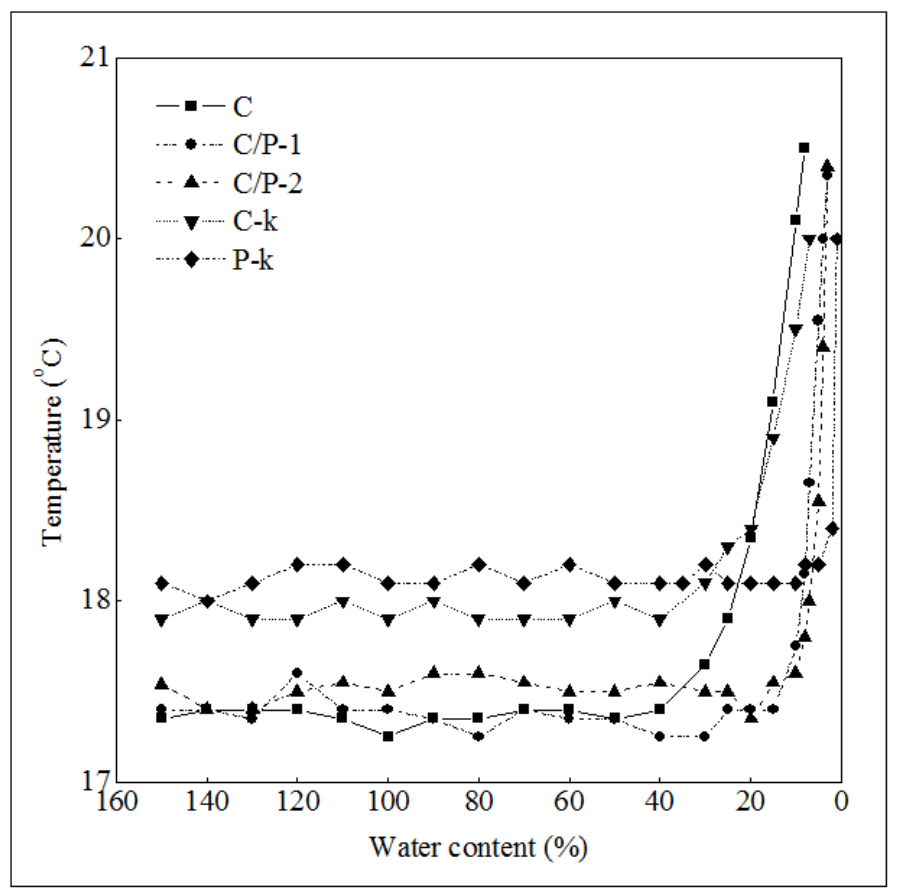

Figure 19. Relationship between water content and fabric temperature during the drying process of all fabric samples. 
Figure 20 presents results concerning the relationship between the temperature difference and the water content of cotton fabric at equilibrium. In this figure, the data points labeled "Weight" represent temperature difference calculated by subtracting fabric temperature shown in Figure 19 from room temperature, while the points labeled " $\mathrm{C}-1$ " to "C-6" represent the results of thermocouple measurements from six replicate trials. These results demonstrate that the measured temperatures and weights are highly reproducible and that thermocouple results are consist with the weight results. At low values of temperature difference, the slope of the plot between water content and temperature difference is quite small, whereas this slope increases significantly at temperatures above approximately $3{ }^{\circ} \mathrm{C}$, corresponding to the water content of about $35 \%$.

Based on the analysis of critical water content, Figure 20 can be divided into two parts, as shown by the two regression lines. When temperature difference reaches to $3^{\circ} \mathrm{C}$, the water content of fabric varies greatly, and during this process, it is difficult to predict water content only by temperature changes of fabric. However, if temperature difference is below $3^{\circ} \mathrm{C}$, the relationship between the water content and temperature difference of each segment is highly in agreement with the regression lines plotted by "Weight" in the experimental trial. It has verified that the relationship between fabric temperature difference and water content of cotton fabric. From the temperature difference, the dry and wet conditions of fabric segment can be obtained, and moreover, the water content of fabric segment can be estimated. We therefore conclude that the measured temperature difference between the fabric and ambient can be used to estimate the water content of the fabric, provided the water content of the fabric is below the critical equilibrium water content for the fabric.

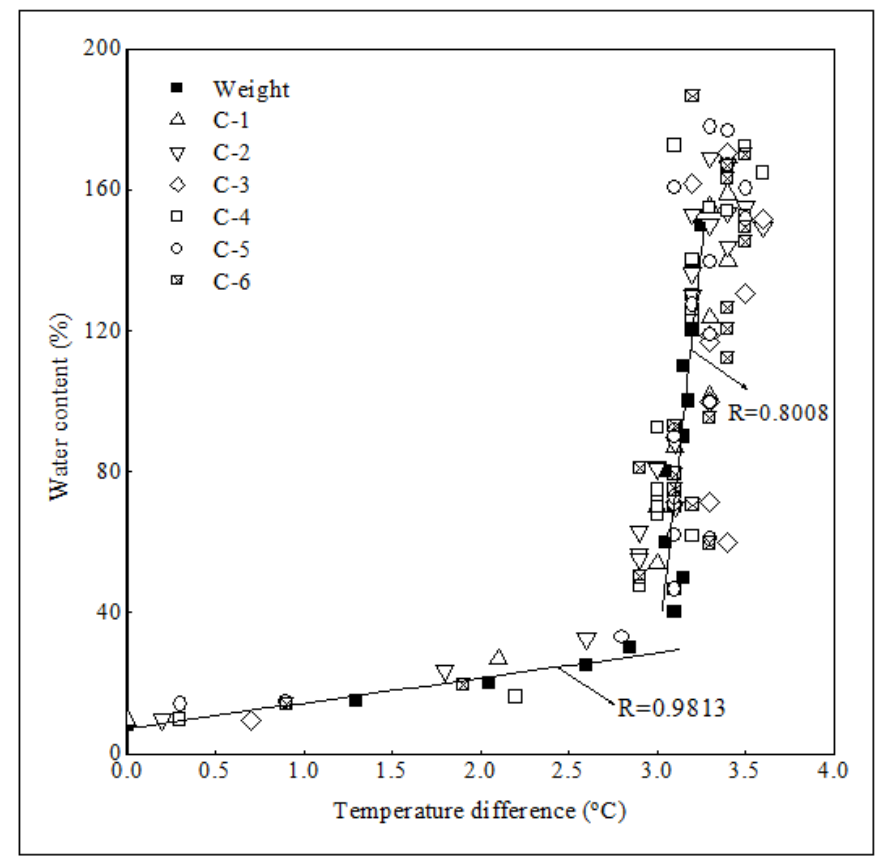

Figure 20. Comparison of results obtained by weighing method and thermocouple array method.

\section{Conclusions}

A new method has been proposed for the measurement of in-plane capillary water flow within fabrics. This technique, using data acquired from a series of thermocouples, is capable of automatically tracking the wicking length versus time. The wicking coefficients obtained by this new method were compared with those found using Byreck method, and the accuracy of the thermocouple method was verified. As the measurement thermocouples are physically small, removable and flexible, this method can be applied to many different kinds of textile structures. Moreover, this method can be used to measure the wicking length with respect to time without the addition of dye to the liquid.

In further trials, the relationship between temperature difference and water content was found based on 
physically weighing fabric specimens and the critical water content was obtained. When the water content of cotton fabric was above the critical water content of about $35 \%$, the temperature difference was essentially constant. However, below this water content, the temperature difference increased rapidly as the water content decreased. Based on these investigations, it appears that it is possible to estimate the water content of fabrics from the thermocouple temperature measurements, so long as the water content of the fabric is lower than the critical value for that material. This method and the associated apparatus are considered to be applicable to many different areas of fabric analysis, including the assessment of wetting in diapers and the dispersion of sweat in sportswear.

\section{Acknowledgement}

This work was supported by Grants for Excellent Graduate Schools, MEXT, Japan. This work was also supported by Grant-in-Aid for Global COE Program by the Ministry of Education, Culture, Sports, Science, and Technology of Japan. This work was also supported by JSPS KAKENHI Grant number 24220012.

\section{References}

1. Erik K. Wetting and wicking. Text Res $J$ 1996; 66: 660-668.

2. Hsieh YL. Liquid transport in fabric structures. Text Res J 1995; 65: 299-307.

3. Rajagopalan D, Aneja AP and Marchal JM. Modeling capillary flow in complex geometries. Text Res $J$ 2001; 71: 813-821.

4. Fangueiro R, Filgueiras A, Soutinho F et al. Wicking behavior and drying capability of functional knitted fabrics. Text Res $J$ 2010; 80: 1522-1530.

5. Patnaik A, Rengasamy RS, Kothari VK et al. Wetting and wicking in fibrous materials. Text Prog 2006; 38: 1-105.

6. Kawase T, Sekoguchi S, Fujii T, et al. Spreading of liquids in textile assemblies: Part I: Capillary spreading of liquids. Text Res $J$ 1986; 56: 409-414.

7. Wang N, Zha AX and Wang JX. Study on the wicking property of polyester filament yarns. Fibers Polym 2008; 9: 97-100.

8. Jiang XY, Zhou XH, Weng M, et al. Image processing techniques and its application in water transport through fabrics. J Fiber Bioeng Inform 2010; 3: 88-93.

9. Perwuelz A, Mondon P and Caze C. Experimental study of capillary flow in yarns. Text Res J 2000; 70 : 333-339.

10. Lord PR. A comparison of the performance of open-end and ring spun yarns in terry toweling. Text Res $J$ 1974; 44: 516-522.

11. Merve KO, Banu N and Cevza C. A study of wicking properties of cotton-arcylic yarns and knitted fabrics. Text Res $J$ 2011; 81: 324-328.

12. Esra C, Alex JF and Steven BW. Fibrous structures with designed wicking properties. Text Res J 2007; 77: 256-264.

13. Rossi RM, Stampfli R, Psikuta A, et al. Transplanar and in-plane wicking effects in sock materials under pressure. Text Res J 2011; 81: 1549-1558.

14. Su CI, Fang JX, Chen XH, et al. Moisture absorption and release of profiled polyester and cotton composite knitted fabrics. Text Res J 2007; 77: 764-769.

15. Japanese Industrial Standard L 1907: 1994. Test method of water absorbency of textiles-5.1.2, Byreck method.

16. Din 53924. Velocity of suction of textile fabrics in respect of water-method determining the rising height. Berlin: Deutsches Institut fur Normung, 1997.

17. Yoneda M and Niwa M, Measurement of in-plane capillary water flow of fabrics. Sen'i Gakkaishi 1992; 48: 288-298.

18. Hsieh YL and Yu B. Liquid wetting, transport, and retention properties of fibrous assemblies. Part I: water wetting properties of woven fabrics and their constituent single fibers. Text Res J 1992; 62: 677-685. 
19. Bayramli E and Powell RL. Experimental investigation of the axial impregnation of oriented fiber bundles by capillary forces. Colloids Surf 1991; 56: 83-100.

20. Ito $\mathrm{H}$ and Muraoka $\mathrm{Y}$. Water transport along textile fibers as measured by an electrical capacitance technique. Text Res J 1993; 63: 414-420.

21. Babu VR and Koushik CV. Capillary rise in woven fabrics by electrical principle, Indian J Fibre Text Res; 2011; 36: 99-102.

22. Zhu $\mathrm{CH}$ and Takatera M. Change of temperature of cotton and polyester fabrics in wetting and drying process, J Fiber Bioeng Inform 2012; 5:433-446.

23. Mhetre $\mathrm{S}$ and Parachuru R. The effect of fabric structure and yarn-to-yarn liquid migration on liquid transport in fabrics. J Text Inst 2010; 101: 621-626.

24. Washburn EW. The dynamic of capillary flow. Phys Rev 1921; 17: 273-283.

25. Kamath YK, Hornby SB, Weigmann HD, et al. Wicking of spin finishes and related liquids into continuous filament yarns. Text Res J 1994; 64: 33-40.

26. Nyoni AB. Liquid transport in Nylon 6.6 woven fabrics used for outdoor performance clothing. In: Vassiliadis S (eds) Advances in modern woven fabrics technology. InTech, 2011, pp.211-240.

27. Haghi AK. Thermal analysis of drying process: A theoretical approach. J Therm Anal Calorim 2003; 74 : 827-842.

28. Richard S. Factors affecting the drying of apparel fabrics. Part I: Drying behavior. Text Res $J$ 1958; 28 : 136-144.

29. Sasaki S, Kubo J. Drying performance of cloths hung in a thermostatic oven (Part 2) The relationship between the drying rate and the surface temperature of wet cloths. Nakumura Gakuen Univ 1980; 13: 129-133. 